\title{
HUBUNGAN PENGETAHUAN DENGAN KEPERCAYAAN DIRI PERAWAT NICU MELAKUKAN PERAWATAN METODE KANGURU DI RUMAH SAKIT X JAKARTA
}

\section{RELATIONSHIP OF CHARACTERISTICS AND KNOWLEDGE WITH CONFIDENCE NICU NURSES TREAT KANGURU METHOD IN HOSPITALS $X$ JAKARTA}

\author{
Novi Diah Ekawati ${ }^{1}$, Tuti Asrianti Utami ${ }^{2}$, Rosa Nora Lina ${ }^{3}$ \\ ${ }^{1,2,3}$ Sekolah Tinggi Ilmu Kesehatan Sint Carolus \\ Korespondensi Penulis : tutichaidir18@gmail.com
}

\begin{abstract}
Abstrak
Bayi berat badan lahir rendah merupakan bayi yang perlu mendapatkan perhatian dan perawatan yang optimal. Perawatan bayi di ruang NICU menggunakan inkubator membuat adanya pemisahan antara ibu dengan bayinya. Perawatan metode kanguru menawarkan suatu kedekatan antara ibu dengan bayinya untuk membantu meningkatkan pertumbuhan dan perkembangan bayi dengan berat badan lahir rendah. Perawat NICU harus memiliki pengetahuan dan kepercayaan diri yang baik dalam mendukung kegiatan Perawatan Metode Kanguru. Tujuan penelitian ini untuk menganalisa hubungan antara pengetahuan dengan kepercayaan diri perawat NICU melakukan PMK. Metode penelitian kuantitatif ini, dengan desain studi potong lintang (cross sectional), telah dilakukan di RS X pada bulan Desember 2020 - Maret 2021. Populasi seluruh perawat ruang NICU dengan pengambilan sampel secara total sampling, pengumpulan data menggunakan kuisioner yang dibagikan kepada 40 responden. Hasil penelitian menjelaskan bahwa sebagian besar responden terdiri dari usia 26-35 tahun $30(75 \%)$ responden, berpendidikan D3 keperawatan $24(60 \%)$ responden, lama bekerja selama 1-5 tahun $16(40 \%)$ responden, belum mengikuti pelatihan PMK $31(77,5 \%)$ responden, memiliki pengetahuan cukup $22(55 \%)$ responden, memiliki kepercayaan diri $20(50 \%)$ responden dan tidak percaya diri sebanyak $20(50 \%)$ responden. Berdasar hasil Analisa (Chi Square) tidak terdapat hubungan antara pengetahuan dengan kepercayaan diri perawat NICU dalam melakukan Perawatan Metode Kanguru dengan $p$ value 0,438 ( $\mathrm{p}$ value >0.05). Perawat di ruang NICU menjadi lebih baik jika memiliki rasa percaya diri dalam melakukan asuhan keperawatan metode kanguru, sehingga bayi dengan berat badan lahir rendah dapat bertumbuh lebih sehat. Penelitian ini merekomendasikan perawat NICU untuk memiliki pengetahuan yang baik tentang PMK sehingga perawat mempunyai percaya diri dalam pelaksanaan PMK.
\end{abstract}

Kata kunci : berat badan lahir rendah, kepercayaan diri perawat, perawatan metode kanguru

\begin{abstract}
Low birth weight babies are babies who need optimal attention and care. Baby Care in the NICU using an incubator creates a separation between mother and baby. The kangaroo method of care offers a close relationship between the mother and her baby to help promote the growth and development of babies with low birth weight. NICU nurses must have good knowledge and confidence in supporting Kangaroo Method Care activities. The purpose of this study was to analyze the relationship between knowledge and confidence in NICU nurses doing PMK. This quantitative research method, with a cross-sectional study design, was carried out at X Hospital in December 2020 - March 2021. The population of all NICU room nurses with total sampling, data collection using questionnaires distributed to 40 respondents. The results of the study explain that most of the respondents are aged 26-35 years, 30 (75\%) respondents, have D3 nursing education, 24 (60\%) respondents, have worked for $1-5$ years, $16(40 \%)$ respondents, have not attended PMK training 31 (77.5\%) respondents, $22(55 \%)$ respondents had sufficient knowledge, $20(50 \%)$ respondents had self-confidence and $20(50 \%)$ respondents were not confident. Based on the results of the analysis
\end{abstract}

Submit / unggah : 29 Oktober 2021, Accepted : 10 Desember 2021

Website : jurnal.stikespamenang.ac.di | Email : jurnal.pamenang@gmail.com 
(Chi-Square) there is no relationship between knowledge and confidence of NICU nurses in performing the Kangaroo Treatment Method with a p-value of 0.438 ( $p$-value > 0.05). Nurses in the NICU will be better off if they have confidence in performing kangaroo nursing care, so babies with low birth weight can grow up healthier. This study recommends NICU nurses have good knowledge about PMK so that nurses have confidence in implementing PMK.

Keywords: low birth weight, nurse confidence, kangaroo method care

\section{Pendahuluan}

Berat badan lahir rendah (BBLR) adalah bayi yang berat lahirnya kurang dari 2500 gram dan terlepas dari usia kehamilannya (Hockenberry et al., 2017). Prevalensi BBLR diperkirakan 15\% - 20\% dari 20 juta bayi yang lahir setiap tahun. Prevalensi tertinggi BBLR di Asia Selatan sebanyak 28\%, Afrika sebanyak 13\% dan Amerika Latin sebanyak 9\% (Sukamti, Maryanah et al., 2020). Secara statistik menunjukkan 90\% kejadian BBLR didapatkan di negara berkembang dan angka kematiannya 35 kali lebih tinggi dibandingkan dengan bayi dengan berat lahir lebih dari 2500 gram (Wati et al., 2019). Prevalensi BBLR tahun 2018 sebanyak $6.2 \%$, presentase ini lebih tinggi dibandingkan dengan tahun 2013 yaitu 5.7\%. Di Indonesia prevalensi BBLR diperkirakan mencapai 2103 dari 18.948 bayi (11.1\%) yang ditimbang dalam kurun waktu 6 sampai 48 jam setelah dilahirkan (Riskesdas, 2018). Hasil Survei Demografi dan Kesehatan Indonesia (SDKI) tahun 2017 menunjukkan Angka Kematian Neonatus (AKN) sebesar 15 per 1.000 kelahiran hidup, tahun $2030 \mathrm{AKN}$ diharapkan akan mencapai Target Pembangunan Berkelanjutan (TPB/SDGs) yaitu sebesar 12/1.000 kelahiran hidup (Kemenkes RI, 2018). Perawatan BBLR yang berkualitas baik dapat menurunkan angka kematian neonatal. Perawatan neonatus yang berkualitas perlu dukungan alat seperti inkubator dan perlengkapan lain di Neonatal Intensive Care Unit (NICU). NICU adalah unit perawatan intensif untuk bayi baru lahir dengan resiko tinggi yang memerlukan perawatan atau tindakan khusus dengan pemakaian alat bantu nafas mekanik, pemberian obat-obatan tertentu dengan pengawasan ketat dari dokter secara terus menerus dengan dukungan fasilitas berteknologi tinggi (Irtanti \& Utami, 2019). Perawatan bayi dengan BBLR di ruang NICU memerlukan tempat inkubator, sehingga membuat adanya pemisahan antara ibu dengan bayi baru lahir. Pemisahan antara ibu dan bayi ini merupakan salah satu penyebab munculnya rasa kurang percaya diri ibu dalam merawat bayinya (Sukamti, Maryanah et al., 2020). Inovasi yang ditawarkan dalam perawatan bayi lahir prematur dengan cara mendekatkan bayi dan ibunya secara langsung adalah perawatan metode kanguru atau disingkat dengan PMK (Deswita et al., 2011).

Perawatan Metode Kanguru (PMK) adalah cara merawat bayi dalam keadaan telanjang (hanya memakai popok dan topi), diletakkan secara tegak/vertikal tengkurap di dada antara kedua payudara ibunya (ibunya telanjang dada) kemudian diselimuti. Kontak kulit bayi dan ibu secara terus-menerus dan bayi memperoleh panas (sesuai suhu tubuh ibunya) melalui proses konduksi (Deswita et al., 2011). PMK bukan hanya sekedar menggantikan peran inkubator, namun juga memberikan berbagai keuntungan yang tidak dapat diberikan inkubator (Maryunani, 2013). PMK telah terbukti mengurangi angka kematian, infeksi, meningkatkan pertumbuhan, tingkat menyusui, meningkatkan thermostasis dan meningkatkan ikatan ibu dan bayi (Atik et al., 2016).

Keberhasilan penerapan PMK diantaranya difasilitasi dengan tersedianya sumberdaya manusia sebagai pemberi layanan perawatan secara professional (Jamali et al., 2019). Perawat merupakan profesi yang selalu berinteraksi dengan pasien selama 24 jam. Interaksi antara perawat dengan pasien diperlukan pengetahuan, keterampilan dan kompetensi perawat untuk meningkatkan kualitas perawatan pasien. Perawat diharapkan mempunyai pengetahuan dan keterampilan terkini dalam memberikan perawatan sesuai dengan kebutuhan pasien (Kusumawati, 2011). Peran perawat selain sebagai pemberi asuhan keperawatan adalah sebagai pendidik dan pengelola dalam memberikan asuhan Keperawatan (Zendrato \& Sri Hariyati, 2018). Pengetahuan perawat tentang PMK sangat mendukung agar dapat menerapkan atau mengaplikasikan PMK secara tepat pada BBLR dengan harapan kualitas asuhan keperawatan pada BBLR akan semakin 
meningkat (Ejakhianghe, 2017). Perawat sebagai pendidik, membantu kesiapan orang tua untuk melakukan PMK dan juga menentukan bahwa bayi tersebut stabil secara medis untuk dilakukan PMK. Perawat neonatal harus memiliki tingkat pemahaman tentang manfaat PMK serta keterampilan untuk memposisikan bayi dengan aman (HendricksMunoz \& Mayers, 2014).

Perawat neonatal harus mendapatkan pelatihan dan peluang untuk mengembangkan diri sehingga mereka dapat memberikan pengetahuan terbaru kepada staf dan orang tua (Solomons \& Rosant, 2012). Perawat membantu melakukan PMK, selain itu perawat harus membekali diri dengan pengetahuan yang baik. Pengetahuan adalah proses tahu dari individu terhadap objek yang diminatinya melalui seluruh proses pancaindera yang dimilikinya (Notoatmodjo, 2014). Pengetahuan seseorang sangat dipengaruhi oleh berbagai hal, salah satunya adalah karakteristik dari individu yang menerima informasi atau pengetahuan tersebut.

Kepercayaan diri merupakan persepsi individu tentang dirinya dan kemampuan yang dimilikinya untuk mengatasi kesulitan dalam melaksanakan tugas tertentu yang berhubungan dengan perubahan perilaku (Karimi et al., 2014; Utami, 2017). Pengetahuan yang memadai tentang manfaat PMK dan pelatihan membuat perawat lebih bersikap positif dan meningkatkan kepercayan diri perawat dalam memberikan asuhan PMK dan dukungan untuk orang tua dalam melakukan PMK (Strand et al., 2014). Angka prevalensi kasus BBLR yang melalui perawatan NICU di Rumah Sakit X Jakarta sangat berubah-ubah tiap tahunnya. Tahun 2018 didapatkan bayi BBLR sebanyak 42 kejadian dari 1486 kelahiran, tahun 2019 kejadian BBLR mengalami kenaikkan menjadi 69 kejadian dari 1504 kelahiran, sedangkan pada bulan Januari-Juni 2020, didapatkan bayi BBLR yaitu 16 kejadian dari total 454 kelahiran.

Penerapan PMK di NICU RS X sudah dilakukan sejak tahun 2015, namun pelaksanaannya masih belum optimal. Hal ini terlihat dari adanya perawat yang masih perlu pendampingan dalam melakukan PMK dan belum semua perawat NICU di RS X tersebut mendapatkan pelatihan tentang teknik PMK. Pengetahuan tentang PMK hanya didapatkan secara turun temurun dari perawat yang lebih senior, inipun hanya bagian dasar-dasar saja. Sebelum melakukan PMK, orang tua biasa menanyakan tentang bagaimana prosedur PMK dilakukan, kapan saja PMK dilakukan, manfaat PMK dilakukan, dan persiapan sebelum PMK. Untuk dapat menjawab pertanyaan - pertanyaan orang tua yang seperti itu terkadang perawat yang belum memiliki pengalaman dalam melakukan PMK masih butuh arahan dari perawat yang lebih senior agar tidak ada kesalahan dalam memberikan informasi. Berdasarkan masalah tersebut diatas maka peneliti tertarik meneliti lebih jauh mengenai "Hubungan pengetahuan dengan kepercayaan diri perawat NICU melakukan Perawatan Metode Kanguru di RS X Jakarta.

\section{Metode Penelitian}

Penelitian kuantitatif ini menggunakan desain cross sectional. Populasi penelitian ini adalah perawat Neonatal Intensif Care Unit (NICU) di RS X Jakarta, RS X1 sebanyak 25 responden, RS X 2 Jakarta sebanyak 9 responden, dan RS X 3 Jakarta sebanyak 6 responden, sehingga berjumlah 40 responden. Penelitian ini dilakukan di ruang Neonatus Intensif Care Unit (NICU), di RS X 1 Jakarta, RS X 2 Jakarta, dan RS X 3 Jakarta. Jumlah sampel dalam penelitian ini sebanyak 40 perawat, tehnik sampling yang digunakan adalah total sampling.

Penelitian ini dilakukan pada bulan Desember 2020-Maret 2021 di RS X Jakarta. Pengumpulan data menggunakan kuisioner yang dibagikan kepada responden. Penelitian ini menggunakan kuisioner yang sudah dilakukan uji validitas dan reliabilitas dari penelitian Adiana, Utami, Paramitha tahun 2021 tentang hubungan antara pengetahuan dan kepercayaan diri dengan sikap perawat dalam pelaksanaan perawatan metode kanguru (PMK) di RS Swasta. Kuisionernya terdiri dari pernyataan pengetahuan tentang PMK menggunakan skala Gutman dan pernyataan kepercayaan diri menggunakan skala Likert. Kuisioner pengetahuan tentang PMK didapatkan hasil $\mathrm{r}$ tabel adalah 0,306 dan hasil reliabilitas didapatkan cronbach's alpha sebesar 0,714. Sedangkan hasil uji valid kuisioner percaya diri didapatkan hasil $r$ tabel adalah 0,306 dan hasil reliabilitas didapatkan cronbach's alpha sebesar 0,738. Sehingga kuisioner pengetahuan tentang PMK dan kepercayaan diri perawat NICU digunakan 
pada penelitian ini. Analisa data univariat dan

bivariat menggunakan uji Chi-square.

\section{Hasil Penelitian}

Tabel 1. Distribusi frekuensi karakteristik responden melakukan Perawatan Metode Kangguru di RS X Jakarta

\begin{tabular}{lll}
\hline Karakteristik & $\begin{array}{l}\text { Frekuensi } \\
(\mathbf{n})\end{array}$ & $\begin{array}{l}\text { Presentase } \\
(\mathbf{\%})\end{array}$ \\
\hline Usia & 5 & \\
17-25 Tahun & $\mathbf{3 0}$ & 12,5 \\
26-35 Tahun & 2 & $\mathbf{7 5}$ \\
36-45 Tahun & 3 & 5 \\
45-55 tahun & & 7,5 \\
\hline Pendidikan & $\mathbf{2 4}$ & $\mathbf{6 0}$ \\
D3-Keperawatan & 16 & 40 \\
S1- Keperawatan & & \\
\hline Lama Bekerja & $\mathbf{1 6}$ & $\mathbf{4 0}$ \\
1-5 Tahun & 15 & 37,5 \\
6-10 Tahun & 6 & 15 \\
11-15 Tahun & 1 & 2,5 \\
16-20 Tahun & 1 & 2,5 \\
21-25 Tahun & 1 & 2,5 \\
>25 Tahun & & \\
\hline Pelatihan & $\mathbf{3 1}$ & $\mathbf{7 7 , 5}$ \\
Belum & 9 & 22,5 \\
Sudah & 40 & 100 \\
\hline Total & &
\end{tabular}

Berdasarkan tabel 1 menjelaskan bahwa sebagian besar responden terdiri dari usia 2635 tahun sebanyak $30(75 \%)$ responden, berpendidikan D3 keperawatan sebanyak 24
(60\%) responden, lama bekerja selama 1-5 tahun sebanyak $16(40 \%)$ responden, sebagian besar belum mengikuti pelatihan PMK yaitu sebanyak $31(77,5 \%)$ responden.

Tabel 2. Distribusi frekuensi pengetahuan responden melakukan Perawatan Metode Kangguru di RS X Jakarta

\begin{tabular}{lll} 
Karakteristik & $\begin{array}{l}\text { Frekuensi } \\
(\mathbf{n})\end{array}$ & $\begin{array}{l}\text { Presentase } \\
(\boldsymbol{\%})\end{array}$ \\
\hline Pengetahuan & & \\
Kurang & 3 & 7,5 \\
Cukup & $\mathbf{2 2}$ & $\mathbf{5 5}$ \\
Baik & 15 & 37,5 \\
\hline Percaya Diri & & \\
Tidak Percaya Diri & 20 & 50 \\
Percaya Diri & 20 & 50 \\
\hline Total & 40 & 100 \\
\hline
\end{tabular}

Tabel 2 diatas menjelaskan bahwa pengetahuan responden tentang PMK di ruang NICU RS X Jakarta sebagian besar responden memiliki pengetahuan cukup sebanyak 22 $(55 \%)$ responden dan memiliki kepercayaan diri sebanyak $20(50 \%)$ responden dan tidak percaya diri sebanyak $20(50 \%)$ responden. 
Tabel 3. Hubungan pengetahuan dengan kepercayaan diri perawat melakukan Perawatan Metode Kanguru di RS X Jakarta

\begin{tabular}{lllllllll}
\hline \multirow{2}{*}{ Pengetahuan } & \multicolumn{3}{l}{$\begin{array}{l}\text { Kepercayaan Diri } \\
\text { Tidak Percaya Diri }\end{array}$} & \multicolumn{2}{l}{ Percaya diri } & \multicolumn{2}{l}{ Jumlah } & \multirow{2}{*}{\begin{tabular}{l}
\multirow{2}{*}{ value } \\
OR
\end{tabular}} \\
& $\mathbf{n}$ & $\mathbf{\%}$ & $\mathbf{n}$ & $\mathbf{\%}$ & $\mathbf{n}$ & $\mathbf{\%}$ & & \\
\hline Kurang & 1 & 33,3 & 2 & 66,7 & 3 & 100 & & \\
Cukup & 13 & 59,1 & 9 & 40,9 & 22 & 100 & 0,438 & 1.044 \\
Baik & 6 & 40 & 9 & 60 & 15 & 100 & & \\
\hline Jumlah & 20 & 50 & 20 & 50 & 40 & 100 & & \\
\hline
\end{tabular}

Tabel 3 diatas menjelaskan bahwa hubungan antara pengetahuan dengan kepercayaan diri dalam pelaksanakan PMK. Responden dengan pengetahuan baik memiliki sikap percaya diri sebanyak 9 responden $(60 \%)$, responden dengan pengetahuan cukup memiliki sikap percaya diri sebanyak 9 responden $(40,9 \%)$, responden dengan pengetahuan kurang memiliki sikap percaya diri sebanyak 2 responden $(66,7 \%)$. Hasil anaisa uji Chi square mendapatkan $p$ value sebesar 0,438 lebih besar dari 0,05, dapat diinyatakan bahwa Ha ditolak yang berarti tidak ada hubungan yang signifikan antara pengetahuan dengan kepercayaan diri perawat dalam pelaksanaan PMK.

\section{Pembahasan}

Pengetahuan adalah hasil tahu dari individu melalui seluruh proses pancaindera yang dimilikinya, diantaranya mata, hidung, telinga dan sebagainya terhadap satu objek. Pengetahuan dapat diperoleh melalui proses dari pengalaman sendiri atau pun pengalaman bersama orang lain (Notoatmodjo, 2014).

Pengetahuan juga dipengaruhi oleh pendidikan seseorang, diketahui bahwa responden dengan pendidikan DIII Keperawatan sebanyak $24(60 \%)$ responden dan S1 Keperawatan sebanyak $16(40 \%)$ responden. Hal ini sejalan dengan penelitian Notoatmojo (2014) bahwa semakin tinggi pendidikan seseorang maka semakin mudah seseorang menerima informasi, dan semakin banyak pengetahuan yang dimilikinya tentang kesehatan (Jamali et al., 2019).

Pengalaman sebagai sumber pengetahuan, dengan cara mengulang pengetahuan dalam menyelesaikan masalah (Notoatmodjo, 2014). Pengalaman bekerja dapat memberikan pengetahuan dan ketrampilan professional selama bekerja sehingga mampu mengambil keputusan (Jamali et al., 2019; Pakpahan \& Sipayung, 2019).

Penelitian oleh Adiana et al., (2021) membagi ketegori pengetahuan perawat menjadi 2 kategori, yaitu kurang dan cukup, dimana responden sebagian besar memiliki pengetahuan yang cukup dengan hasil 40 $(66.7 \%)$ responden. Kepercayaan diri adalah keyakinan yang dimiliki atas kemampuan yang ia miliki untuk menyusun serta menjalankan setiap kegiatan yang dibutuhkan guna menghasilkan sesuatu yang diinginkan (Surya et al., 2018).

Penelitian ini tidak sejalan dengan penelitian (Sambo \& Reskiany, 2018) yang menjelaskan bahwa ada pengaruh yang signifikan antara pendidikan kesehatan tentang perawatan metode kanguru terhadap kepercayaan diri perawat dan bidan. Peneliti berasumsi bahwa responden yang memiliki pengetahuan cukup merasa kurang percaya diri. Hal ini disebabkan karena kurangnya pengalaman, dukungan, dan pemahaman responden tentang manfaat PMK.

Almutairi \& Ludington (2016) menjelaskan bahwa perawatan kanguru tidak dilaksanakan dikarenakan kurangnya pengetahuan dan keterampilan perawat. Penelitian ini menjelaskan bahwa $p$ value $=$ 0,000 dengan metode quasi experimen pretestpostest dengan melakukan pelatihan PMK selama 2-5 hari. Penelitian oleh Amalia \& Herawati (2018) menjelaskan bahwa adanya hubungan antara pengetahuan ibu dengan pelaksanaan PMK yang menghasilkan nilai $p$ value 0,004. Pengetahuan yang meningkat akan membuat perubahan perilaku dan bila perilaku didasari pengetahuan, kesadaran dan sikap positif maka perilaku itu akan bersifat langgeng. Penelitian Phaphali Adzitey (2017) menjelaskan bahwa sikap perawat yang 
antusias dan positif tentang pelaksanaan PMK saja tidak cukup, harus didukung oleh pengetahuan dari perawat tersebut. Meskipun berpengetahuan cukup tetapi responden memiliki sikap kurang baik, hal ini dikarenakan kurangnya pemahaman tentang manfaat PMK dan kurangnya dukungan dari rekan kerja ketika melaksanakan PMK. Responden yang memiliki pengetahuan kurang namun mempunyai sikap baik, ini disebabkan karena responden mempunyai pemahaman yang baik terhadap manfaat dari pelaksanaan PMK.

Almutairi \& Ludington (2016) menjelaskan bahwa penyebab perawatan kanguru tidak dilaksanakan karena kurangnya percaya diri perawat. Kepercayaan diri seseorang merupakan kemampuan mereka untuk mengatur dan melaksanakan tindakan dalam mencapai tujuan. Orang yang percaya bahwa mereka dapat melakukan sesuatu untuk mengubah lingkungan cenderung akan bertindak dan lebih berhasil dari orang yang tidak memiliki kepercayaan diri (Bandura dalam Fattah, 2017). Phaphali Adzitey (2017) menjelaskan bahwa sikap perawat yang antusias dan positif tentang pelaksanaan PMK saja tidak cukup, harus didukung oleh pengetahuan dari perawat tersebut. Penelitian oleh Almutairi \& Ludington (2016) menjelaskan bahwa pengetahuan, keterampilan dan percaya diri adalah hal penting dan menjadi dasar dalam keberhasilan

\section{Daftar Pustaka}

Adiana, N. K., Utami, T. A., \& Ningsih, P. W. (2021). Hubungan Karakteristik, Pengetahuan Dan Kepercayaan Diri Dengan Sikap Perawat Dalam Pelaksanaan Perawatan Metode Kanguru Di RS Swasta Tipe C. Jurnal Surya Muda, 3(2), 133-146. https://doi.org/10.38102/jsm.v3i2.92

Almutairi, W. M., \& Ludington, S. (2016). Kangaroo Care Education Effects on Nurses' Knowledge and Skills Confidence. Article in The Journal of Continuing Education in Nursing. https://doi.org/10.3928/0022012420161017-11

Amalia, L., \& Herawati, E. (2018). Hubungan Pengetahuan dan Sikap Dalam Pelaksanaan Perawatan Metode Kangguru. Jurnal Pendidikan Keperawatan Indonesia, 4(2), 152-161. https://doi.org/10.17509/jpki.v4i2.13658

Atik, N. S., Nugraheni, S. A., \& Cahyo, K. (2016). Analisis Implementasi Program Perawatan pelaksanaan PMK. Kepercayaan diri bisa mempengaruhi sikap dan perilaku seseorang. Peneliti berpendapat meskipun percaya diri tetapi bila tidak didukung dengan pengetahuan dan pengalaman yang cukup, serta dukungan rekan kerja dan manajemen seseorang bisa bersikap tidak baik. Peneliti menyimpulkan sikap seseorang tidak hanya dipengaruhi oleh kepercayaan diri saja, melainkan harus didukung dengan pengetahuan, dukungan rekan kerja serta pengalaman mereka.

\section{Kesimpulan}

Tidak ada hubungan signifikan antara pengetahuan dengan kepercayaan diri perawat NICU melakukan perawatan metode kanguru. Saran bagi pelayanan Rumah Sakit untuk meningkatkan pengetahuan dan kepercayaan diri perawat dalam mendukung pelaksanaan Perawatan Metode Kanguru (PMK) dengan memberikan kesempatan pada seluruh perawat NICU untuk mendapatkan dan mengikuti pelatihan khusus tentang Perawatan Metode Kanguru (PMK) sehingga PMK dapat terlaksana pada seluruh BBLR secara maksimal.

\section{Ucapan Terimakasih}

Peneliti mengucapkan terimakasih kepada Rumah Sakit X Jakarta dan STIK Sint Carolus serta semua pihak yang telah membantu sehingga penelitian ini dapat terlaksana dengan baik dan lancar.

Metode Kanguru (PMK) Dan Partisipasi Pasien Pada Pelayanan Kesehatan Bayi Berat Lahir Rendah (BBLR) (Studi pada Pasien di Rumah Sakit Mardi Rahayu Kudus). Jurnal Manajemen Kesehatan Indonesia, 4(2), 98-108. https://doi.org/10.14710/jmki.4.2.2016.98108

Cristianti Dwi Irtanti, \& Soetadji, T. A. U. (2019). Knowledge The Use of Continous Positive Airway Pressure (CPAP) In Neonatus. Caring: Indonesian Journal of Nursing Science, 1(2), 95-102. https://doi.org/10.32734/ijns.v1i2.3249

Deswita, D., Besral, B., \& Rustina, Y. (2011). Pengaruh Perawatan Metode Kanguru terhadap Respons Fisiologis Bayi Prematur. Kesmas: National Public Health Journal, $5(5)$, 227. https://doi.org/10.21109/kesmas.v5i5.131

Fattah, H. (2017). Kepuasan Kerja dan Kinerja Pegawai. Palembang: Elmatera

Hendricks-Munoz, K. D., \& Mayers, R. M. (2014). 
A Neonatal Nurse Training Program in Kangaroo Mother Care (KMC) Decreases Barriers to KMC Utilization in the NICU. American Journal of Perinatology, 31(11), 987-991. https://doi.org/10.1055/s-00341371359

Hockenberry, M. ., Wilson, D., \& Rodgers, C. (2017). Wong's Essentials of Pediatrics Nursing. Elsevier.

Jamali, Q. Z., Shah, R., Shahid, F., Fatima, A., Khalsa, S., Spacek, J., \& Regmi, P. (2019). Barriers and enablers for practicing kangaroo mother care (KMC) in rural Sindh, Pakistan. PLoS ONE, 14(6), 1-15. https://doi.org/10.1371/journal.pone.02132 25

Karimi, F. Z., Bagheri, S., Tara, F., khadivzadeh, T., \& Mousavi Bazaz, S. M. (2014). Effect of Kangaroo Mother Care on breastfeeding self-efficacy in primiparous women, 3 month after child birth. http://ijogi.mums.ac.ir/article_3517.html

Kemenkes RI. (2018). Profil Kesehatan Indonesia. Kementrian Kesehatan Indonesia. In Pusdatin.Kemenkes.Go.Id.

Kusumawati, N. N. (2011). Gambaran tingkat pengetahuan perawat tentang perawatan metode kanguru di RSAB Harapan Kita. Telah dipublikasikan. Fakultas Keperawatan, Universitas Indonesia, Depok.

Maryunani, A. (2013). Asuhan bayi dengan berat badan lahir rendah. TIM. Jakarta.

Notoatmodjo, S. (2014). Ilmu Perilaku Kesehatan. Renika Cipta.

Pakpahan, H. M., \& Sipayung, R. (2019). Hubungan Pengetahuan Dan Sikap Ibu Dalam Pelaksanaan Perawatan Metode Kanguru (Pmk) Dengan Peningkatan Berat Badan Bayi Di Ruang Nicu Rsia Stella Maris Medan. Jurnal Darma Agung Husada, VI(2), 110-116.

Phaphali Adzitey, S. (2017). Knowledge and Attitude of Nurses in the Tamale Metropolis toward Kangaroo Mother Care (KMC). In Annals of Medical and Health Sciences Research. Annals of Medical and Health Sciences Research. https://www.amhsr.org/articles/knowledgeand-attitude-of-nurses-in-thetamalemetropolis-toward-kangaroo-mothercare-kmc-4024.html

Riskesdas. (2018). Hasil Riset Kesehatan Dasar Tahun 2018. Kementrian Kesehatan RI, 220.
Roselynd Ejakhianghe ESEWE. (2017). Developing strategies to enhance implementation of early Kangaroo Mother Care (KMC) guidelines in health care facilities in Edo State, Nigeria. 4(November), 9-15.

Sambo, M., \& Reskiany, R. (2018). Pengaruh Edukasi Tentang Perawatan Metode Kanguru (PMK) Terhadap Self Efficacy Perawat Dan Bidan Di Puskesmas Sungai Bali. Jurnal Mitrasehat, 8(1), 126-136.

Solomons, N., \& Rosant, C. (2012). Knowledge and attitudes of nursing staff and mothers towards kangaroo mother care in the eastern sub-district of Cape Town. South African Journal of Clinical Nutrition, 25(1), 33-39. https://doi.org/10.1080/16070658.2012.117 34400

Strand, H., Blomqvist, Y. T., Gradin, M., \& Nyqvist, K. H. (n.d.). Kangaroo mother care in the neonatal intensive care unit: staff attitudes and beliefs and opportunities for parents. https://doi.org/10.1111/apa.12527

Sukamti, Maryanah, S., Oktalia, J., Antarsih, N. R., \& Aticeh, I. S. (2020). Kangaroo Mother Care at Low Birth Weight. Asian Journal of Applied Sciences, 8(1), 56-60. https://doi.org/10.24203/ajas.v8i1.6077

Surya, P., Putra, P., Luh, D., Pande, K., \& Susilawati, A. (2018). Hubungan Antara Dukungan Sosial Dan Self Efficacy Dengan Tingkat Stres Pada Perawat Di Rumah Sakit Umum Pusat Sanglah. In Jurnal Psikologi Udayana (Vol. 5, Issue 1).

Utami, T. A. (2017). Promosi Kesehatan Nola Pender Berpengaruh Terhadap Pengetahuan dan Kepatuhan ODHA Minum ARV. Jurnal Ners Dan Kebidanan Indonesia, 5(1), 58. https://doi.org/10.21927/jnki.2017.5(1).5867

Wati, R. C. R., Etika, R., \& Yunitasari, E. (2019). Pengaruh Perawatan Metode Kanguru Terhadap Respon Fisiologis Bayi Berat lahir Rendah. Pediomaternal Nursing Journal, $5(2)$, 175. https://doi.org/10.20473/pmnj.v5i2.13333

Zendrato, M. V., \& Sri Hariyati, R. T. (2018). Optimalisasi Pengelolaan Asuhan Keperawatan di Instalasi Rawat Jalan Rumah Sakit X. Jurnal Persatuan Perawat Nasional Indonesia (JPPNI), 2(2), 85. https://doi.org/10.32419/jppni.v2i2.86 